\title{
The Encyclopaedia in the Digital Era: A New Beginning or just the Beginning of the End
}

\author{
Bruno Kragić \\ The Miroslav Krleža Institute of Lexicography \\ Frankopanska 26, Zagreb, Croatia \\ bruno.kragic@lzmk.hr
}

During the last 10 to 15 years we have witnessed the transition of encyclopaedias from the printed into web form, most visible through the global spreading of Wikipedia, through her numerous varieties, as the most used encyclopaedia today. However, this opens the question about the change in the encyclopaedic principles and the encyclopaedic concept of knowledge. Besides the obvious change in the modes of use, there is the question regarding the encyclopaedic concept itself: collaborative online encyclopaedia is in itself never-ending and all-encompassing while the traditional, printed one had to define its range, number and dimension of the entries. Thus, while collaborative online encyclopaedia is more propulsive, open or "democratic", the "old" type was closer to the original encyclopaedic concept of the transmission of the knowledge. There are several reasons why online encyclopaedias have replaced printed ones: the financial one - Wikipedia is free - is as obvious as the social one - the reflection of the changes in the information field where crowd-sourcing has in many ways replaced experts. Furthermore, printed, paper encyclopaedias are not as easily and thoroughly searchable as their digital counterparts or, to put it more specifically, they are searchable in a different way. Also, they can be neither easily nor constantly updated. In addition, they are far more limited in size (just to illustrate this, the last printed edition of Encyclopaedia Britannica had about 70,000 entries, while English Wikipedia has more than 5,490,000). But, all this presupposes that the main goal of encyclopaedia is the first-hand information about more or less everything, with prominent place given to the current issues or recent events. Printed encyclopaedia, on the other hand, had another underlying goal, some sort of its grand ambition - to provide an overview of all (relevant) human knowledge and to put it into a coherent, logical order. Finally, in the tradition of the most ambitious such project - that of the Diderot's Encyclopédie, it had the ambition not only to order knowledge but to reorder it, to be used as enlightenment's tool. In theory, online encyclopaedia can have similar ambitions, but the aforementioned goal requires a fixed body of articles, needs a clear and stable knowledge frame - to know what is to be put inside and what remains irrelevant. For online users almost everything is relevant and has to be put in encyclopaedia. Collaborative online encyclopaedia as such has no system, thus one can question is it encyclopaedia at all. Although the mapping of the human knowledge, encircling all that has to be put in the encyclopaedia has 
always been the mark of utopia, and almost all readers of printed encyclopaedias consulted articles in a more or less similar vein as they consult online encyclopaedias, the encyclopaedia in a printed form, encyclopaedia of the past was a sort of the library distilled down into an organized essence of human knowledge while the encyclopaedia of the present (and future?), the online one, is a sort of warehouse of books and information.

Key words: encyclopaedia, collaborative online encyclopaedia, Wikipedia, knowledge organisation 